\title{
Manpower for Better Health Services
}

\author{
SURGEON GENERAL WILLIAM H. STEWART
}

$\mathrm{M}$ ORE AND MORE, the physician is functioning as a manager - a job for which he is not specifically prepared, either by training or by tradition. Typically, he used to be a soloist. At most he was the director of a small, compact team in which each individual's role was clearly delineated. Today he must direct the efforts and energies of a growing number and variety of health workers.

As the managerial function of the physician increases, so does his dependence upon others. If he is to succeed in the task for which he has spent a quarter of a century in educational preparation, each member of his corps of supporters must perform to specifications. Their skills must interlock in the right way at the right time. And the highest possible wagerhuman life-is riding on the outcome.

Thus the training of supportive health workers is of much more than academic interest to the physician. He stakes his professional life on their competence every day. As medicine advances in complexity, his dependence cannot possibly diminish; it can only increase.

The magnitude of the training challenge is enormous. Today in medicine, dentistry, nursing, and the other health professions there are perceived needs for over 500,000 additional workers-a number far greater than the national training capacity. Two things must be done. First, we must augment and make the best possible use of programs and facilities for training professional health workers. Second, we must give greatly increased effort to the analysis of health service functions, to the de- velopment of meaningful technician and assistant groups, and to the development and support of training programs which will prepare people to work together much more effectively.

The number of workers in the health occupations increased at a rate of 3 percent a year between the 1950 and the 1960 census. If this rate continues, the totals will increase from about 2.4 million this year to some 3.3 million 10 years from now.

The health service industry has many workers not in the health occupations. Their number has grown even faster. In the health occupations the annual rate of increase has been 3 percent. The number in the health service industry has been increasing at a rate of about 4 . percent. If growth should continue at between 3 and 4 percent, we would add 1.0 to 1.5 million health service workers in the next 10 years.

\section{Training Health Workers}

There is also a qualitative component to training. We cannot neglect quality of preparation to meet the overwhelming challenge of numbers. The cost of carelessness or error is too great. The price of ineptitude is not only the loss of somebody's job but perhaps the loss

Dr. Stewart, Surgeon General of the Public Health Service, delivered the address on which this paper is based at the Joint Conference on Job Development and Training for Workers in Health Services, sponsored by the U.S. Department of Labor and the U.S. Department of Health, Education, and Welfare, Washington, D.C., February 17, 1966. 
of somebody else's life. We must do more than turn out a million health workers in 10 years. We must turn out a million good ones.

Moreover, these people cannot be successfully trained in isolation from the health complex of which they will become a part. Teamwork in medicine is not an assembly line in which each man tightens his particular bolt, more or less irrespective of what happens before and after. Skills don't just touch each other; they are interwoven. A good nurse's aide is constantly growing in her understanding of the nurse's job. A good nurse develops many of the capabilities of the physician.

Many of the barriers that now exist are arbitrary. They were placed by the traditions of another era and are maintained by thinking more appropriate to a guild of the Middle Ages than to a modern profession. There is a need for career ladders in the health professions. I think this need extends through the subprofessional levels as well, crossing the no man's land where the prefix "sub" is tacked onto the word "professional." I might add parenthetically that we ought to find a better word than that patronizing term "subprofessional"-a word that is used only by professionals.

Our aim is not just to recruit and retain bodies. At every entrance level, we want to challenge the people with promise. For many bright young men and women who might join the health enterprise after leaving high school, the road to a medical degree would seem impossibly long. But there is no reason for us to train them in such a way that we put a heavy lid on their aspirations.

Today, in order to advance upward in the health disciplines, it is generally necessary to go back to the beginning and start over. Academic credits acquired in pursuit of one occupational goal rarely count toward a higher goal, and work experience is generally undervalued. This is extremely discouraging to the individual. It is also extremely wasteful of talent that will always be in short supply. The guild system is a luxury we cannot afford.

\section{Channeling Manpower}

Obviously there is no single answer to the problem of providing health manpower to meet the demand of the future. Many courses of action are already underway, under many sponsorships, and designed to meet many separate needs. This is a healthy condition. It would become unhealthy only if each separate course of action should become, in turn, a self-contained compartment to be buttressed and defended, building a new set of rigidities into a system that is desperately in need of the fluid and flexible.

This will not happen if the schools and institutions carrying out the training, and the agencies to which they turn for support, keep their eyes firmly fixed on the purpose of the whole endeavor-the provision of better health services for more people. All these separate channels must converge upon health care. By the same token, someone must keep track of the changing and growing manpower resource. Someone needs to be able to say, authoritatively, which channels are overflowing and what new courses must be developed.

The primary burden rests squarely upon the health professions themselves. We must furnish the answers to the basic questions: What kinds of training? For how many? And finally, after training, what? How shall we make use of the outpouring of human talent and energy that these training programs will generate? How can we best mobilize this growing resource and direct it toward the health needs of the people we serve?

At the outset, we have to admit that we have not been overwhelmingly successful in using the talent we already have. Medical research has been quick to catch the accelerating tempo of our times. By comparison, medical practice has been slow. We are barely beginning to exploit the potential of automation. The organizational patterns of health service are not yet generally adapted to the widespread delivery of the right care to the right patient at the right time. We have not yet mastered the effective employment of specialization. We are just starting to pass through the managerial revolution that has reshaped industry and science.

There are, however, many hopeful signs. Routine chores are increasingly delegated to assistants. Computers are being allowed to do the things they can do faster and better than people. I believe the day is rapidly approaching when health professionals and their asso- 
ciates will be using their highest skills far more efficiently in behalf of their patients.

Even when that day arrives, some questions will remain to be answered. The abstract problem of applying health manpower to health need is at root a human problem and must be considered in human terms. I should like to conclude by posing a couple of these human problems for which I have no handy solution. The problems are cast in terms of health professionals, nurses and physicians, but they are similarly applicable to other health disciplines.

\section{Human Problems}

Consider, first, the classic dilemma of the nursing profession. It is axiomatic that for every practicing professional nurse several have fallen by the wayside. Either they do not finish school or they enter the profession and subsequently leave it for marriage and a family. The mystery is not why the nurses leave, but why the profession has not accommodated itself to the natural and inevitable. It seems to me that there must be ways whereby a nurse can be married and raise a family without being irrevocably lost to her profession.

I have the impression, for example, that maternity leave provisions in most health enterprises are far less liberal than those in industry and government. I am not aware of any systematic provision of refresher courses for nurses who would like to return to the profession after a few years' absence. I don't know of many institutions in which a nurse can practice a few hours a day, or a couple of days a week, to contribute her much needed skills at times which do not conflict with her family responsibilities.

I have heard one serious proposal to build, next to a hospital, a large and attractive apartment house specifically designed for nurses and their families. Day nursery services for young children and other features would help overcome the many minor hardships that now discourage the married woman from practicing her profession. Whether or not this becomes a reality, it represents creative thinking in the right direction. We need more of it.

The second problem concerns a young physician who, after about 25 years of education, is ready to finish the last year of his internal med- icine residency and set up practice. What are the chances that he will locate where his skills are needed most, and how can those chances be influenced in favor of applying talent to need?

We talk glibly about equal access to health services as a major goal for the future. But health professionals are human beings. They want to locate where the money is-or where they think it is. They want to locate where they can continue the stimulating professional associations to which they have become accustomed and want their children to go to the best schools. The deck is heavily stacked against equal access to their services for rural Americans, for slum-dwelling Americans, for smalltown Americans.

Again I have no all-inclusive answers to propose. The idea of locating physicians by fiat would be totally unacceptable in our society. Certain strictly economic incentives, such as forgiveness features in loan programs, have been tried with inconclusive results. Wé know that physicians who choose to practice in small towns and rural areas are usually those with rural or smalltown origins; but we know also that a very small proportion of medical students come from such areas, and that many of them are won over by the advantages of the metropolitan environment.

Somehow, the conditions of practice in areas of special need must be made attractive and challenging. In terms of one important factor, the stimulating professional association, I believe we are making a significant start in the regional medical programs for heart disease, cancer, and stroke. Under this concept, the health services of an entire region will be linked to a central focal point of medical excellence, with built-in provisions for continuing professional education, interchange of personnel, and systematic consultation and referral on individual cases.

But we still have a long way to go to counteract the unfortunate tendency for the rich to get; richer and the poor to get poorer in terms of available health services. As with our other problems, we shall need all the creative thinking we can find in the days ahead.

The necessity for thinking in large numbers -hundreds of occupations and millions of workers-carries with it an implicit danger. 
We are dealing with health care. Health care is perhaps the most compellingly human of all occupations.

In mobilizing our army of health workers, let us remember that it is not an army. We have no battalions and regiments to be pressed into service and ordered wherever the need is greatest.

Rather, we are dealing with individual human beings who, we hope, will choose to enlist in the health enterprise and serve it to the height of their capacity. Their free choice can be our greatest asset. If we perform our training functions well, and if we design our health resources so as to encourage full individual development, we will achieve the kind of competence and dedication we need to advance the health of our people.

\section{Education Notes}

Graduate Programs in Rehabilitation Nursing. New York University is offering graduate programs at the master's, sixth year, and doctoral levels. Scholarship funds are available to qualified applicants. For information and application forms write: Dr. June S. Rothberg, Director, Graduate Program in Rehabilitation Nursing, New York University School of Education, Washington Square, New York, 10003.

Traineeships for Physical Therapists. The University of North Carolina will administer a Public Health Service grant to help qualified physical therapists obtain a degree in public health. The traineeships are intended to prepare physical therapists to accept responsibilities of administration, consultation, and supervision in community health agencies.

Information about stipends and curriculum is available from Lydia S. Holley, Assistant Professor, University of North Carolina School of Public Health, Chapel Hill, 27514.

Hawaii's School of Public Health. The University of Hawaii School of Public Health is offering programs leading to the degrees of master of public health and master of science in public health. Its curriculum will emphasize biostatistics, environmental sanitation, epidemiology, international health, maternal and child health, population dynamics, and public health administration, education, engineering, laboratory techniques, and nutrition.

In addition to providing instruction in the public health sciences, this new school is expected to offer community health services and to encourage, develop, and conduct health research in Hawaii and the Asian-Pacific communities.

Information is available from the Graduate Division Office, University of Hawaii, 2540 Maile Way, Honolulu, Hawaii 96822.

Graduate Program in Areawide Planning. The University of Michigan School of Public Health has extended its program in medical care administration to include preparation for careers in areawide planning of medical care services and facilities. The program leads to the master of public health degree and can be completed in 1 to 2 years. Public Health Service traineeship awards are available. They provide payment of tuition and monthly stipends of $\$ 250-\$ 400$ plus $\$ 30$ for each dependent. Additional information is available from the Department of Medical Care Organization, Room 3547, School of Public Health, University of Michigan, Ann Arbor 48104.

Degrees in Environmental Health Sciences. Graduate study leading to master of science and doctor of philosophy degrees in environmental health sciences is offered at the University of California. The program is for holders of baccalaureate degrees in biological, chemical, engineering, or physical sciences who wish to qualify for teaching, research, or managerial positions in industrial hygiene, air resources, radiological health, and environmental biology.

Several kinds of financial assistance are available to qualified students.

Inquiries about admission to the programs should be directed to Dean, School of Public Health, University of California, Berkeley. 